\title{
SKRINING FITOKIMIA EKSTRAK DAN FRAKSI ETANOL 70\% DAGING BUAH PEPAYA (Carica papaya L.)
}

\section{PHYTOCHEMICAL EXTRACTS AND FRACTION 70\% ETHANOLIC OF PAPAYA FRUIT FLESH}

\author{
Definingsih Yuliastuti ${ }^{*}$, Wahyunita Yulia Sari ${ }^{2}$, Dian Islamiyati ${ }^{3}$ \\ 1,2,3 Stikes Serulingmas Cilacap \\ `Email : ${ }^{\star}$ defie.farmasi@gmail.com, ${ }^{2}$ wahyunitayulia@gmail.com, ${ }^{3}$ dyan.21manca@gmail.com
}

\begin{abstract}
ABSTRAK
Pepaya merupakan salah satu tanaman yang banyak dibudidaya oleh petani Indonesia dan menjadi sumber asupan buah-buahan. Buah pepaya dalam bentuk ekstrak dan fraksi sering dimanfaatkan khususnya dalam bidang kosmetika. Kandungan kimia yang terkandung dalam buah pepaya bertanggungjawab dalam memberikan aktivitas kosmetologi. Penelitian ini bertujuan untuk mengetahui kandungan senyawa yang terdapat dalam ekstrak dan fraksi etanol $70 \%$ daging buah pepaya. Metode yang digunakan pada penelitian ini adalah metode eksperimental. Penelitian dilakukan dengan membuat ekstrak dan fraksi kemudian hasilnya diuji secara kualitatif kandungan senyawa kimianya. Berdasarkan penelitian ekstrak etanol $70 \%$ daging buah pepaya mengandung vitamin $\mathrm{C}$, polifenol, flavonoid dan steroid sedangkan fraksi etanol daging buah pepaya mengandung vitamin $\mathrm{C}$, polifenol dan flavonoid. Hasil tersebut dapat dijadikan dasar untuk penelitian selanjutnya membuat sediaan tabir surya.
\end{abstract}

Kata kunci: ekstrak, fraksi, pepaya, skrining fitokimia

\begin{abstract}
Papaya is one of the plants that is widely cultivated by Indonesian farmers and is a source of fruit intake. Papaya fruit in the form of extracts and fractions is often used especially in the cosmetics fields. The chemical content contained in papaya fruit is responsible for providing cosmetological activities. This study aims to determine the content of compounds contained in the extract and fraction of ethanol $70 \%$ papaya flesh. The method used in this study is an experimental method. The study was conducted by making extracts and fractions then the results were tested qualitatively for the content of their chemical compounds. Based on the research of $70 \%$ ethanol extract papaya flesh contains vitamin C, polyphenols, flavonoids and steroids while ethanol fraction papaya flesh contains vitamin $\mathrm{C}$, polyphenols and flavonoids. These results can be used as a basis for further research to make sunscreen preparations.
\end{abstract}

Keywords: extract, fraction, papaya, phytochemical

\section{PENDAHULUAN}

Pepaya merupakan salah satu tanaman yang banyak dibudidaya oleh petani Indonesia dan menjadi sumber asupan buah-buahan. Buah pepaya dalam bentuk ekstrak dan fraksi sering dimanfaatkan khususnya dalam bidang kosmetika. Kandungan kimia yang terkandung dalam buah pepaya bertanggungjawab dalam memberikan aktivitas kosmetologi. 
Skrining fitokimia dilakukan untuk memberikan gambaran tentang golongan senyawa yang terkandung dalam tanaman yang diteliti. Metode skrining fitokimia dilakukan dengan pengujian warna dengan menggunakan suatu pereaksi warna. ${ }^{1} \mathrm{Hal}$ yang berperan penting dalam skrining fitokimia adalah pemilihan pelarut dan metode ekstraksi. ${ }^{2}$ Penelitian ini merupakan penelitian pendahuluan yang berjudul "Uji Kualitatif Ekstrak dan Fraksi Etanol 70\% Daging Buah Pepaya (Carica papaya L.) untuk mengetahui kandungan senyawa yang terdapat dalam ekstrak dan fraksi etanol $70 \%$ daging buah pepaya.

\section{METODE}

\section{Bahan}

Bahan yang digunakan dalam penelitian ini meliputi daging buah pepaya, etanol $70 \%$, $\mathrm{N}$-heksan, etil asetat, $\mathrm{KMnO} 40,1 \%, \mathrm{FeCl} 3$ $10 \%$, Amonia, $\mathrm{HCl} 1 \%$, Dragendorff, Mayer, Klorofom, H2SO4 Pekat.

\section{Alat}

Alat yang digunakan dalam penelitian ini meliputi seperangkat alat gelas, blender, toples kaca, kain mori, waterbath, sendok tanduk, dan timbangan analitik.

\section{Tahapan Penelitian}

1. Pembuatan Simplisia

Buah pepaya didapatkan dari Desa Karangkemiri Kecamatan Maos Kabupaten Cilacap, buah pepaya yang digunakan adalah buah pepaya yang matang dipohonnya. Kemudian buah tersebut disortasi dari pengotor. Lalu dilakukan pencucian dengan air mengalir hingga bersih, setelah itu dihaluskan dan dikeringkan dengan cara dijemur dibawah sinar matahari dengan ditutupi kain hitam sampai kering. Kemudian dihaluskan menggunakan blender hingga menjadi serbuk simplisia yang sesuai. Setelah itu disimpan dalam wadah kering tertutup rapat dalam ruangan terlindung dari cahaya matahari. ${ }^{3}$

2. Pembuatan Ekstrak Daging Buah Pepaya

Serbuk simplisia daging buah pepaya dimaserasi dengan pelarut etanol 70\% selama 24 jam dan pada 2 jam pertama dilakukan pengadukan. Hasil maserasi disaring dengan kain mori. Selanjutnya, residu dimaserasi kembali hingga warna coklat bening. Filtrat yang diperoleh disatukan dan dipekatkan di atas waterbath dengan suhu $40^{\circ} \mathrm{C}$ sampai diperoleh ekstrak kental.

3. Pembuatan Fraksi Daging Pepaya

Ekstrak kental etanol $70 \%$ yang dihasilkan difraksinasi dengan $100 \mathrm{ml} \mathrm{N}$ heksan menggunakan corong pisah, dengan pengulangan 2 kali. Fraksi etanol $70 \%$ yang didapat kemudian dikumpulkan dan difraksinasi dengan 50 $\mathrm{ml}$ etil asetat menggunakan corong pisah dengan pengulangan 4 kali sehingga didapatkan fraksi etanol $70 \%$ yang optimum. ${ }^{4}$ Analisis Fitokimia Ekstrak dan Fraksi

Ekstrak dan fraksi diuji menggunakan metode tabung dengan cara mengambil sedikit sempel ektrak dan fraksi etanol daging buah pepaya, lalu ditambahkan reagen sesuai senyawa yang diidentifikasi. Senyawa kimia yang diidentifikasi pada ekstrak dan fraksi etanol $70 \%$ daging buah pepaya adalah vitamin $\mathrm{C}$, polifenol, flavonoid, antosianin, alkaloid, dan steroid.

a. Uji Vitamin C

Ekstrak atau fraksi sebanyak $1 \mathrm{ml}$ ditambahkan $5 \mathrm{ml}$ aquadest dikocok lalu ditambahkan $\mathrm{KMnO} 4$ 0,1\% $10 \mathrm{ml}$. Jika timbul warna coklat menunjukan adanya senyawa vitamin C. ${ }^{5}$

b. Uji Polifenol

Sebanyak satu $\mathrm{ml}$ ekstrak atau fraksi ditambahkan dengan beberapa tetes $\mathrm{FeCl} 310 \%$. Jika hasilnya terbentuk warna hijau atau hijau kehitaman, biru atau ungu berarti hasil analisa positif mengandung polifenol. ${ }^{6}$.

c. Uji Flavonoid

Kertas saring ditetesi dengan larutan ekstrak atau fraksi, jika berwarna kuning kemungkinan mengandung flavonoid. Jika diuapi ammonia terbentuk warna kuning yang intensif berarti hasil analisa positif mengandung flavonoid. ${ }^{6}$

d. Uji Alkaloid

Ekstrak atau fraksi sebanyak 1 gram dipanaskan dalam tabung reaksi denagn $\mathrm{HCl} 1 \% 10 \mathrm{ml}$ selama 30 menit diatas penangas air mendidih. Kemudian disaring dan filtrat dibagi menjadi dua tabung reaksi sama 
banyak. Lalu dalam tabung reaksi I ditambahkan pereaksi Dragendorff (3 tetes). Jika terbentuk endapan berwarna merah bata menunjukan adanya senyawa alkaloid. Selanjutnya dalam tabung reaksi II ditambahkan pereaksi Meyer (3 tetes). Terbentuknya endapan berwarna putih menunjukan adanya senyawa alkaloid. ${ }^{7}$

e. Uji Steroid

Ekstrak atau fraksi sebanyak 0,5 gram dalam tabung reaksi ditambahkan 2 $\mathrm{ml}$ etanol $70 \%$ kemudian diaduk, ditambahkan $2 \mathrm{ml}$ kloroform, kemudian ditambahkan $2 \mathrm{ml} \mathrm{H}_{2} \mathrm{SO}_{4}$ pekat dengan cara diteteskan pelanpelan dari sisi dinding tabung reaksi. Pembentukan cincin merah menunjukan adanya steroid. ${ }^{8}$

HASIL

Tabel 1. Hasil Uji Kualitatif Ekstrak Etanol 70\% Daging Buah Pepaya

\begin{tabular}{clc}
\hline $\begin{array}{l}\text { Senyawa } \\
\text { Aktif }\end{array}$ & \multicolumn{1}{c}{ Hasil Uji } & Hasil (+/-) \\
\hline Vitamin C & $\begin{array}{l}\text { Terbentuk warna } \\
\text { coklat pudar }\end{array}$ & + \\
Polifenol & $\begin{array}{l}\text { Terbentuk warna } \\
\text { hijau kehitaman }\end{array}$ & + \\
Flavonoid & $\begin{array}{l}\text { Terlihat warna } \\
\text { kuning lebih intensif } \\
\text { Tidak terbentuk } \\
\text { Alkaloid }\end{array}$ & + \\
Steroid & $\begin{array}{l}\text { Terbentuk cincin } \\
\text { merah kehitaman }\end{array}$ & + \\
\hline
\end{tabular}

Tabel 2. Hasil Uji Kualitatif Fraksi Etanol 70\% Daging Buah Papaya

\begin{tabular}{clc}
\hline $\begin{array}{c}\text { Senyawa } \\
\text { Aktif }\end{array}$ & \multicolumn{1}{c}{ Hasil Uji } & Hasil (+/-) \\
\hline Vitamin C & $\begin{array}{l}\text { Terbentuk warna } \\
\text { coklat lebih gelap }\end{array}$ & + \\
Polifenol & $\begin{array}{l}\text { Terbentuk warna } \\
\text { hijau kehitaman }\end{array}$ & + \\
Flavonoid & $\begin{array}{l}\text { Terlihat warna } \\
\text { kuning lebih intensif }\end{array}$ & + \\
Alkaloid & $\begin{array}{l}\text { Tidak terbentuk } \\
\text { endapan }\end{array}$ & - \\
Steroid & $\begin{array}{l}\text { Tidak terbentuk } \\
\text { cincin merah } \\
\text { kehitaman man }\end{array}$ & - \\
& & \\
\hline
\end{tabular}

Keterangan :

$+=$ positif mengandung senyawa hasil
- $=$ tidak mengandung senyawa hasil
pengujian

\section{PEMBAHASAN}

Hasil Pembuatan Simplisia

Daging buah pepaya yang diperoleh dari Desa Karangkemiri Kecamatan Maos Kabupaten Cilacap sebanyak $3,5 \mathrm{~kg}$ selanjutnya disortasi basah yang bertujuan untuk memisahkan daging buah pepaya dari kotoran-kotoran yang menempel dan tidak diperlukan. Setelah sortasi basah dilakukan daging buah pepaya tersebut selanjutnya dihaluskan agar mudah dalam proses pengeringan. Pengeringan dilakukan sampai daging buah pepaya kering selama beberapa hari dibawah sinar matahari. Pengeringan dilakukan dengan tujuan untuk menghilangkan kandungan air yang terdapat pada daging buah pepaya agar pada saat penyimpanan simplisia terbebas dari jamur. Daging buah pepaya yang sudah kering dihaluskan, hal ini dilakukan dengan tujuan untuk memperluas permukaan antara serbuk simplisia dengan pelarut saat proses ekstraksi. ${ }^{3}$

\section{Hasil Pembuatan Ekstrak}

Metode maserasi dipilih untuk mencegah perusakan komponen-komponen dari daging buah pepaya yang bersifat termolabil selain itu metode maserasi digunakan karena maserasi termasuk metode yang cukup sederhana dan ekonomis. Etanol dipilih sebagai cairan penyari karena pelarut ini dapat melarutkan hampir semua metabolit sekunder yang terkandung dalam daging buah pepaya. Selain itu, etanol juga bersifat tidak toksik. ${ }^{9}$ Hasil ekstraksi daging buah pepaya didapatkan ekstrak kental berwarna coklat kekuningan.

\section{Hasil Pembuatan Fraksi}

Fraksinasi merupakan proses pemisahan antara zat cair dengan zat cair. Fraksinasi dilakukan secara bertingkat berdasarkan tingkat kepolarannya yaitu dari non polar, semi polar, dan polar. ${ }^{10}$ Senyawa flavonoid merupakan senyawa polar yang dibawa oleh pelarut etanol $70 \%$. Proses pertama fraksinasi yaitu melarutkan dengan $\mathrm{N}$ Heksan. N-Heksan yang bersifat non polar akan melarutkan senyawa yang bersifat non polar dalam ekstrak etanol $70 \%$ daging buah pepaya. Proses ini diulangi sebanyak 2 kali 
untuk memaksimalkan proses pelarutan tersebut. Selanjutnya fraksi etanol yang didapat di fraksinasikan kembali dengan etil asetat yang bersifat semi polar agar senyawa yang bersifat semi polar dapat terbawa oleh etil asetat.

\section{Analisis Fitokimia Ekstrak}

Hasil analisis Ekstrak Etanol $70 \%$ daging buah pepaya terbukti mengandung senyawa vitamin C, polifenol, flavonoid, dan steroid. Uji kualitatif vitamin C dilakukan dengan menggunakan uji pereaksi warna dengan melarutkan ekstrak dengan aquadest kemudian direaksikan dengan $\mathrm{KMnO} 4$ warna $\mathrm{KMnO} 4$ hilang dan lama-lama menjadi warna coklat, hal ini disebabkan karena reaksi antara vitamin $\mathrm{C}$ dengan $\mathrm{KMnO} 4$ akan menghilangkan warna dari KMnO4.11 Dari hasil uji kualitatif yang didapatkan disimpulkan bahwa ekstrak daging buah pepaya mengandung vitamin C.

Ekstrak daging buah pepaya mengandung senyawa polifenol. Hal ini dapat dilihat dari perubahan warna yang terjadi pada suatu penambahan $\mathrm{FeCl} 3$ dari warna kecoklatan menjadi warna hijau kehitaman. ${ }^{6}$ Analisa fitokimia senyawa flavonoid pada ekstrak daging buah papaya didapatkan hasil yang positif. Hal ini dapat dilihat dari perubahan warna dari kuning pudar menjadi kuning yang lebih intensif dari ekstrak daging buah pepaya yang diuapi dengan ammonia menyatakan bahwa flavonoid merupakan senyawa yang mengandung dua cincin aromatik dengan gugus hidroksil lebih dari satu. Reduksi dengan ammonia menghasilkan warna kuning pada flavonoid. ${ }^{6}$ Senyawa alkaloid pada ekstrak daging buah pepaya didapatkan hasil yang negatif, hal ini dapat dilihat dari tidak adanya endapan berwarna merah bata setelah penambahan pereaksi dragendroff dan tidak adanya endapan berwarna putih setelah penambahan pereaksi mayer. ${ }^{7}$

Senyawa steroid pada ekstrak daging buah pepaya didapatkan hasil yang positif, hal ini dapat dilihat dari terbentuknya cincin merah kecoklatan setelah penambahan kloroform dan $\mathrm{H}_{2} \mathrm{SO} 4{ }^{8}$

\section{Analisis Fitokimia Fraksi}

Hasil analisis fitokimia vitamin $\mathrm{C}$ pada fraksi etanol $70 \%$ daging buah pepaya ditandai dengan berubahnya warna fraksi sebelum ditetesi reagen dari hitam kecoklatan menjadi coklat pudar. Hasil ini didukung oleh pernyataan Auterhoff (1987) bahwa sampel yang mengandung vitamin $\mathrm{C}$ jika ditambahkan aquades dan $\mathrm{KMnO} 4$ akan berubah warna menjadi coklat. ${ }^{11}$

Polifenol fraksi daging buah pepaya menunjukan reaksi positif ditandai dengan berubahnya warna fraksi sebelum ditetesi reagen dari hitam kecoklatan menjadi hitam kehijauan. Bukti kualitatif untuk menunjukkan adanya polifenol dapat diperoleh dengan menggunakan pereaksi $\mathrm{FeCl} 3$ polifenol akan membentuk warna hijau dan hitam kehijauan akibat reaksi dengan besi (III) klorida. Senyawa fenol dengan gugus hidroksil semakin banyak memiliki tingkat kelarutan dalam air semakin besar atau bersifat polar, sehingga dapat terekstrak dalam pelarut-pelarut polar. ${ }^{6}$

Hasil uji kualitatif senyawa flavonoid dilakukan dengan mengambil sedikit sampel, diteteskan di atas kertas saring, kemudian diuapkan dengan ammonia. ${ }^{6}$ Flavonoid merupakan senyawa yang mengandung dua cincin aromatik dengan gugus hidroksil lebih dari satu. Reduksi dengan ammonia menghasilkan warna kuning pada flavonoid. Berdasarkan hasil uji flavonoid sampel fraksi etanol $70 \%$ daging buah pepaya mengalami perubahan warna dari kuning pudar menjadi kuning lebih intensif.

Uji kualitatif senyawa steroid pada fraksi daging buah pepaya didapatkan hasil yang negatif, dilihat dari tidak terbentuknya cincin merah kecoklatan setelah penambahan kloroform dan $\mathrm{H} 2 \mathrm{SO} 4$. Hal ini dapat disebabkan karena senyawa steroid yang bersifat nonpolar akan ikut terlarut dengan $\mathrm{N}$-Heksan yang juga bersifat nonpolar pada saat fraksinasi. ${ }^{8}$

\section{SIMPULAN DAN SARAN}

Berdasarkan hasil analisis fitokimia, ekstrak daging buah pepaya positif mengandung vitamin $\mathrm{C}$, polifenol, flavonoid dan steroid sedangkan fraksi etanol daging buah 
pepaya mengandung vitamin $\mathrm{c}$, polifenol dan flavonoid. Hasil analisis fitokimia ekstrak dan fraksi etanol dapat dilanjutkan untuk membuat sediaan tabir surya.

\section{UCAPAN TERIMAKASIH}

Terimakasih kepada LPPM Serulingmas yang telah memberikan bantuan dana untuk penelitian ini.

\section{DAFTAR PUSTAKA}

1. Widayanti, S. M., A. W. Permana, H. D. Kusumaningrum. Kapasitas Kadar Antosianin Ekstrak Tepung Kulit Buah Manggis (Garcinia mangostana L.) pada Berbagai Pelarut dengan Metode Maserasi. J. Pascapanen, 6 (2): 61-68 ; 2009.

2. Kristianti, A. N, N. S. Aminah, M. Tanjung, dan B. Kurniadi. Buku Ajar Fitokimia. Surabaya: Jurusan Kimia Laboratorium Kimia Organik FMIPA Universitas Airlangga. P.47-48; 2008.

3. Rahayu, W.S., Hartanti, D., Hidayat, N. Pengaruh Metode Pengeringan terhadap Kadar Antosian pada Kelopak Bunga Rosela (Hibiscus Sabdariffa L.), Pharmacy, Vol. 06, No. 02 ; 2009.

4. Eka, I. S. Aktivitas Antibakteri Ekstrak Etanol Daun Kelapa Sawit (Elaeis guineensis Jacq) dan Fraksi-fraksinya Terhadap Escherichia coli dan pseudomonas aeruginosa serta Profil KLTnya, Skripsi, Fakultas Farmasi Universitas Muhamadiah, Surakarta ; 2014.

5. Ramadhani, F. S. Kandungan Antibakterial dalam Daun Sirih, UNEJ Jurnal I (1): 1-3; 2013.

6. Robinson, T. Kandungan Organik Tumbuhan Tinggi, Diterjemahkan oleh Kokasih Padmawinata, Bandung: ITB ; 1995.

7. Tiwari, P., Kumar, B., Kaur, M., Kaur G. Kaur $\mathrm{H}$. Phytochemical Screening And Extraction: A Review. International Pharmaceutica Science, 1 (1). 98-106 ; 2011.

8. Khoirani N. Karakterisasi Simplisia dan Standarisasi Ekstrak Etanol Herba Kemangi (Ocimum americanum L.), Skripsi, Universitas Negri Semarang ; 2013. 